\title{
ПРИОРИТЕТНОЕ ОБСЛУЖИВАНИЕ СТАТУТА ИНВАЛИДА И ПРИНЦИПА ПРИОРИТЕТНОСТИ ПРИ ОФОРМЛЕНИИ НЕДВИЖИМОСТИ
}

\section{ОРИГИНАЛЬНАЯ СТАТЬЯ}

NETO, Alexandre Moura Lima ${ }^{1}$, AGUAIR, Alessandra Anchieta Moreira Lima de ${ }^{2}$, NETO, Haroldo Corrêa Cavalcanti ${ }^{3}$

NETO, Alexandre Moura Lima. AGUAIR, Alessandra Anchieta Moreira Lima de. NETO, Haroldo Corrêa Cavalcanti. Приоритетное обслуживание статута инвалида и принципа приоритетности при оформлении недвижимости. Revista Científica Multidisciplinar Núcleo do Conhecimento. Год 06, эд. 09, Vol. 03, c. 45-63. Сентябрь 2021 года. ISSN: 2448-0959, Ссылка доступа: https://www.nucleodoconhecimento.com.br/закон/приоритетное-обслуживание, DOI: 10.32749/nucleodoconhecimento.com.br/ru/97619

\section{СВОДКА}

Настоящее исследование направлено на анализ очевидного противоречия между приоритетной заботой о статусе инвалида и принципом приоритетности регистрации недвижимости, то есть, если эта правовая гарантия, дает инвалиду приоритет при указании прав в нотациях. Что касается используемой методологии, то следует отметить, что в отношении целей настоящего исследования это исследование классифицируется как описательное и пояснительное, а что касается средств, то оно классифицируется как библиографическое с использованием таких материалов, как книги, статьи,

\footnotetext{
${ }^{1}$ Магистр культуры и общества Федерального университета Мараньян (UFMA). ORCID: https://orcid.org/0000-0002-7232-8449

2 Он имеет степень магистра окружающей среды в аспирантуре по окружающей среде Университета Ceuma. ORCID: https://orcid.org/0000-0003-4017-1579

${ }^{3}$ Специализация в области права недвижимости. ORCID: https://orcid.org/0000-0003-1746-1965
}

RC: 97619

Доступно в: https://www.nucleodoconhecimento.com.br/закон/приоритетноеобслуживание 
журналы и доклады по этому вопросу. Исследование также характеризуется как качественный подход. Он был призван продемонстрировать, что инвалид имеет право, гарантированное Законом 13.143/2015, на быстрое, эффрективное и индивидуальное обслуживание, в том числе в Реестре записей о недвижимости, но не пользуется привилегиями ввиду регистрационного приоритета с учетом принципа приоритета регистрации. В результате из решений, принятых зарегистрированными судами São Paulo, было установлено, что конкретное положение Закона № 6.015/1973 имеет преимущественную силу в отношении права на приоритетную опеку некоторых публичных лиц, Закон 13.143/2015, поскольку оно является материальным правом приоритета, и понимается, что предоставление приоритетного права вне требований ст. 186 Закона № 6.015/1973 понимается как предоставление приоритетного ухода за пределами требований ст. 186 Закона № 6.015/1973, будет представлять собой неоспоримое оскорбление правовых норм, что поставит под угрозу служение праву на равенство, что также является предпосылкой Статута инвалидов.

Ключевые слова: положение об инвалиде, регистрация недвижимого имущества, принцип приоритета.

\section{1. ЗНАКОМСТВО}

Повседневная жизнь людей с особыми потребностями сложна, учитывая их ограниченность и недостаточную подготовку общества к их получению, как в отношении инфраструктуры, так и менталитета людей, таким образом, они в конечном итоге оказываются социально изолированными, такие виды деятельности, как веселье, учеба и работа, которые являются простыми и рутинными задачами, становятся проблемой, с которой приходится сталкиваться.

Как подчеркивает Carlos Henrique Ribeiro da Silva (2008), отсутствие терпимости между различными на протяжении всей истории приводило к тому, что к

RC: 97619

Доступно в: https://www.nucleodoconhecimento.com.br/закон/приоритетноеобслуживание 
меньшинствам всегда относились относительно агрессивно и запутанно, навешивая ярлыки, сегрегируя, дискриминируя и исключая тех, кто отклонился от стандарта, который формируется из гегемонистской модели. Еще один очень распространенный фрактор, вызванный непониманием различий между людьми, заключается в человеке, считающегося другим, который предполагает очень специфические отношения, такие как самонаказание, изоляция и агрессивность. Таким образом, считается, что отсутствие толерантности к разным имеет исторические корни, хотя многое уже продвинулось по отношению к предмету.

Долгое время в Бразилии инвалид считался недееспособным, с социальными изменениями этот фракт видоизменялся и эти люди стали признаваться субъектами права и способными принимать свои решения, настолько, что в 2015 году Закон № 13.146 изменил Гражданский кодекс, введя Статут инвалидов. По словам Lago (2016), публикация этого Статута направлена на преодоление благосостояния и преодоление барьеров для людей с ограниченными возможностями, как предпосылка для обеспечения права на достоинство, цивилизованность и полноценное участие в жизни общества. Однако, по мнению автора, приоритет, предоставляемый этим людям Статутом, противоречит принципу приоритета при регистрации недвижимости в соответствии с Законом 6.015/1973 и Гражданским кодексом в порядке представления титулов, что является основным направлением данного исследования. Таким образом, в настоящем эссе будет предпринята попытка обсудить приоритет в Статуте инвалидов по сравнению с приоритетом, описанным в Законе о публичных записях (Закон 6.015/73). Занимая в качестве ориентира вопрос: пользуется ли инвалид, с учетом инвалидности, привилегиями перед лицом другого, при освящении регистрационного приоритета?

$\mathrm{RC}: 97619$

Доступно в: https://www.nucleodoconhecimento.com.br/закон/приоритетноеобслуживание 
Принцип приоритета в законодательстве о недвижимости состоит в том, что титул, представленный в первую очередь перед реестром недвижимости, всегда будет иметь приоритет в процедурах регистрации. Согласно ст. 186 Закона о публичных записях (Закон 6.015 / 73), «порядковый номер будет определять приоритет титула, и это предпочтение реальных прав, даже если одно и то же лицо представляет более одного титула одновременно», так что приоритет будет определен для того, кто первым подаст право собственности в реестре недвижимости. А в протоколе нотариуса «все титулы будут иметь порядковый номер, присвоенный им из-за строгой последовательности их предъявления» (ст. 182).

На протяжении последних столетий бразильская система регистрации постоянно модифицировалась с помощью законодательства, которое направлено на мониторинг эволюции общества в целом, обеспечивая безопасность, публичность и эффективность сделок с недвижимостью как для тех, кто в них участвует, так и для тех, кто в этом заинтересован. Согласно Lima (2011), как нотариальная, так и регистрационная деятельность выступают в качестве средства социального умиротворения, обеспечивая публичность, подлинность, безопасность и эфрективность правовых актов превентивным образом.

Важно подчеркнуть, что, хотя нотариальные и регистрационные действия связаны, их не следует путать. Benício (2005) поясняет, что это различие можно увидеть, когда речь идет о функции регистратора и нотариуса (нотариуса), где первый действует с целью узаконивания и опубликования действий, а второй включает консультирование в их функциях с последующей легитимацией, подлинность и формализация правовых актов. Продолжая различать эти два вида деятельности, автор заявляет, что нотариус выполняет в качестве основной ффункции динамическую безопасность ${ }^{[4]}$, в то время как регистратор -

$\mathrm{RC}: 97619$

Доступно в: https://www.nucleodoconhecimento.com.br/закон/приоритетноеобслуживание 
статическую безопасность ${ }^{[5]}$, короче говоря, в то время как нотариус стремится защитить actum (акт), регистратор может опубликовать dictum (сказал).

Деятельность, осуществляемая в соответствии с нотариальным правом и регистрационными сканированиями, должна рассматриваться в их социальной значимости, как указывает Ceneviva (2008), их важность обусловлена объемом действий, который включает в себя от рождения до смерти, запись и гласность всех правовых актов, совершенных гражданами в течение их жизни, таких как брак, развод, совместное использование, товарно-материальные запасы, договоры купли-продажи, среди прочего, упорядочивая все совершаемые действия. Таким образом, это деятельность, непосредственно связанная с повседневной жизнью людей.

Социальная значимость данного исследования подчеркивается, учитывая, что в нем участвует меньшинство населения, которое нуждается во внимании при реализации своих прав, и может лучше прояснить о возможных конфликтах с принципом приоритета при регистрации недвижимости, а также о профессиональной и академической значимости, поскольку многие до сих пор являются противоречиями, которые вращаются вокруг темы, осталось, с небольшим количеством исследований, проведенных и опубликованных по рассматриваемой проблеме, поэтому это исследование остается оправданным.

Что касается используемой методологии, то на основе Maria Cecilia de Souza Minayo (2007) подчеркивается, что в отношении целей это исследование классифицируется как описательное и объяснительное и, что касается средств, классифицируется как библиографическое, с использованием материалов, доступных для общественности, таких как книги, статьи, журналы и доклады по этому вопросу. Исследование также характеризуется как чисто качественный подход. За основу было взято то, что писали другие авторы, будучи в состоянии понять различные точки зрения на предмет, направляя исследование наилучшим образом, чтобы сделать исследование надежным.

$\mathrm{RC}: 97619$

Доступно в: https://www.nucleodoconhecimento.com.br/закон/приоритетноеобслуживание 
В этом контексте, как указывалось ранее, настоящее исследование направлено на анализ противоречия между приоритетной заботой о статусе людей с ограниченными возможностями и принципом приоритетной регистрации недвижимости.

\section{2. ЛЮДИ С ОГРАНИЧЕННЫМИ ВОЗМОЖНОСТЯМИ В ИСТОРИЧЕСКОМ КОНТЕКСТЕ}

C начала времен появляются записи о людях с особыми потребностями. Культурная идея инвалидности, импотенции и зависимости людей с двигательными трудностями пересекает культуры, общества, социокультурные группы, религии и социальные практики. Нарушение ожидания родителей с рождением детей, затронутых каким-либо типом двигательных проблем, приобретение некоторых последствий от болезней или несчастных случаев, безусловно, являются трудными событиями и переживаются во многих культурах нетипичным образом (GUGEL, 2011).

По словам Débora Fazolin Koyama (2017), люди с фризическими недостатками всегда сталкивались с различными ситуациями изоляции и сегрегации перед обществом, в период Древней Греции это особенно изображал городгосударство Спарта, поскольку дети, которые родились с какой-то инвалидностью, считались бесполезными для этого общества и бросались в пропасть.

Débora Fazolin Koyama (2017) говорит, что на протяжении всей истории люди с ограниченными возможностями всегда вели большую борьбу за жизнь и завоевание своего пространства в обществе, поскольку культура, навязанная обществом, всегда маргинализировала их и действовала исключительным образом с этими людьми.

RC: 97619

Доступно в: https://www.nucleodoconhecimento.com.br/закон/приоритетноеобслуживание 
Некоторые из прав инвалидов стали признаваться только во Всеобщей декларации прав человека, и с тех пор был дан удар по тому, что станет стандартизацией основополагающих принципов для этих людей, с этого момента возникло: принцип достоинства человеческой личности, принцип равенства, среди других защитных норм. (КОYАМА, 2017)

Древний Египет, по словам Clemente (2015, стр. 34), был известен как «Земля слепых, потому что его люди постоянно страдали от глазных инфекций, что приводило к слепоте». С другой стороны, есть исторические записи о том, что в местах Древней Греции и Спарты детей с уродствами бросали в лесах или выбрасывали из ущелий.

Римские законы древности не защищали людей с ограниченными возможностями, напротив, узаконивали родителей убивать своих детей, через практику утопления, брошенных в корзинах на реке Тибр или в других священных местах, некоторые из которых выставлялись и использовались в качестве развлечения в цирках. Исследования, проведенные Lourenzetto (2006), подтверждают, что в первые четыре столетия христианской эры не было никакого значимого выражения, которое выступало бы за включение людей с ограниченными возможностями в качестве субъектов достоинства и прав.

В древности сохранилось мало записей об отношениях общества с инвалидами в повседневной жизни. Через библейские отрывки можно воспринимать существовавую в то время дискриминацию в отношении людей с ограниченными возможностями, потому что они всегда упоминаются как нищие или отвергаются общиной, то есть они жили на грани социального и общинного сосуществования. Многие считали, что эти люди были наказаны богами (Lourenzetto, 2006, стр. 3).

В средние века инвалидность считалась метафизическим явлением, определяемым одержимостью демонами или божьим наказанием. Такие люди рассматривались как «обладатели зла из-за пакта с дьяволом», оправдание,

$\mathrm{RC}: 97619$

Доступно в: https://www.nucleodoconhecimento.com.br/закон/приоритетноеобслуживание 
используемое для социальной легитимизации крайнего использования костра в качестве наказания (MAINIERI; ROSA, 2012).

Считалось, что такая практика позволяла унизить и победить предполагаемого врага, которого нужно было победить. Для Maria Aparecida Gugel (2011) помимо предоставления людям с ограниченными возможностями особых способностей колдунов, выжившие дети были разлучлены со своими семьями и почти всегда высмеивались.

Marcella Lourenzetto (2006) ссылается на папские документы, что в случае, когда человек с психическими расстройствами бежит от своего разума, он считался дьявольским существом, продолжая преследоваться, пытаться и истребляться. В 15 веке такие индивидуумы еще не воспринимались как человеческие существа.

В этих примерах ясно показано, как сегрегация и фатализм влияют на людей с проблемами слепоты и любых других, которые убегали от установленных стандартов как обычно (BIANCHETTI; FREIRE, 2007). Наказание за ампутацию также использовалось в качестве контроля и наказания предателей в римских конституциях императора Льва III, процесс, который преобладал в Римской империи и на Востоке.

Рассуждения, введенные благородно в период инквизиции, приняли практику сжигания людей, которые вносили в свое тело какое-то различие, считающееся ненормально, или которые представляли различные идеи статус-кво или вели себя таким образом, который считался неподходящим. По этой причине в заявлениях инквизиции и в оправданиях Церкви нет утверждений о том, что она сжигала людей. Как утверждают Lucídio Bianchetti и Ida Maria Freire (2007, стр. 33), Церковь созволгласила такое действие, как «[...] очищение пламенем». Другое объяснение существования слепых, немых, парализованных, безумных и прокаженных заключалось в том, что они были задуманы как:

$\mathrm{RC}: 97619$

Доступно в: https://www.nucleodoconhecimento.com.br/закон/приоритетноеобслуживание 
[...] Божьи инструменты, чтобы предупредить мужчин и женщин о надлежащем поведении или предоставить ему возможность заниматься благотворительностью. Таким образом, несчастье одних давало средства спасения другим. (BIANCHETTI; FREIRE, 2007, с. 33).

По словам Maria Aparecida Gugel (2011), процесс людей с инвалидностью будет признан людьми достоинства и ценности, пришедшими с первых больниц благотворительности. Для автора между 1214 и 1270 годами король Luís IX основал первую больницу для слепых жертв крестовых походов. Построение новых представлений об инвалидности было исторически возможно только в шестнадцатом веке, когда технические и научные достижения позволили появить различные концепции в медицине.

Только в 16 веке, с научными достижениями в области медицины, появились первые диссонировки высказывания о лечении инвалидов (GUGEL, 2011).

Большинство мужчин и женщин были ограничены своей повседневной жизнью, жалким образом, вовлеченным в производство для пропитания. С постепенным преобладанием рыночного производства, возможности накопления, развития науки и новых технологий, получается относительное господство над природой. Благодаря этому процессу были созданы материальные, социальные и культурные условия для построения освободительных процессов, позволяющих пройти сферу необходимости для свободы.

Только в 16 веке был возможен другой исторический процесс, отличный от предыдущей исторической ситуации. С достижениями в медицине, которые произошли в 17 веке, ффизическая инвалидность стала пониматься как объект изучения медицинской практики. Процесс медикализации недостатков подразумевался в критике исторически присутствующих видений, что в каждом человеке председательствовало болезненное состояние, наличие злых демонов, влияющих на здоровье и болезни (BIANCHETTI; FREIRE, 2007).

$\mathrm{RC}: 97619$

Доступно в: https://www.nucleodoconhecimento.com.br/закон/приоритетноеобслуживание 
Метафизические объяснения религиозной сфреры сталкиваются с позитивистской научной парадигмой, так что теологический взгляд на различие теряет силу, но влияет на теоретические основы органикистской интерпретации. В 17 веке была развязана великая обитель всех тех, кто не участвует в Вселенском Разуме, который зарождался. Тот, кто показал отсутствие разума ни в одной из его форм, как логический, политический, моральный разум, был замкнут (BIANCHETTI; FREIRE, 2007).

Только с середины девятнадцатого века и далее стали появляться первые учреждения по уходу за людьми с ограниченными фризическими возможностями. Долгое время к таким людям относились только как к пациентам, нуждающимся в особом уходе, как к людям с низким потенциалом и многочисленными ограничениями. В Бразилии в тот же период по приказу D. Pedro II были созданы Императорский институт слепых детей и Императорский институт глухонемых, что считается одним из первых бразильских взглядов на интеграцию инвалидов в общество. (SOUSA, 2012).

Однако создание замкнутых устройств также породило процессы сегрегации социальной среды, в результате чего было построено то, что Erving Goffman (2008, стр. 13) определяет как стигма, «[...] особый тип отношений между атрибутом и стереотипом», понимаемый в контексте человеческих отношений, а не субстантивно. «Атрибут, который стигматизирует кого-то, может подтвердить нормальность других».

Проблема инвалидности приобретает еще один фокус из-за наблюдения за сдвигом парадигмы, кивком в 1970-х годах прошлого века, интегративные действия пропагандируются для того, чтобы способствовать присутствию / включению людей с ограниченными возможностями в те же социальные сферы, что и другие. Однако эта возможность предстает как нечто утопическое в своей реальной функциональности, потому что, как объясняет Erving Goffman (2008, стр. 134):

$\mathrm{RC}: 97619$

Доступно в: https://www.nucleodoconhecimento.com.br/закон/приоритетноеобслуживание 
Особая ситуация стигматизированного заключается в том, что общество говорит ему, что он является членом более широкой группы, что означает, что он нормальный человек, но также и то, что он в некоторой степени «другой», и что было бы абсурдно отрицать это различие. Само различие исходит от общества, потому что в целом, прежде чем различие станет важным, оно должно быть коллективно концептуализировано обществом в целом.

Таким образом, включение этой общественности в различные социальные сореры увеличивается с каждым годом, хотя фризические возможности, материально-материальные ресурсы и подготовка специалистов по уходу за людьми с особыми потребностями по-прежнему являются ненадежными, сосредоточив это исследование на правах этих граждан, в частности на интеграции, интеграции и равенстве, основанном на основном принципе достоинства человеческой личности.

\section{3. ПРАВА ЧЕЛОВЕКА С АКЦЕНТОМ НА ЛЮДЕЙ С ОГРАНИЧЕННЫМИ ВОЗМОЖНОСТЯМИ}

Права человека с акцентом на инвалидов, помимо достоинства человеческой личности и равенства, должны подчеркивать право на мобильность и город, а также образование и здравоохранение, учитывая, что они являются решающими фракторами для обеспечения социальной интеграции этих людей. На протяжении всего эволюционного процесса человеческой цивилизации происходил поиск прав, начиная от передвижения и заканчивая самостоятельным обращением в государственной и частной среде.

Исторически сложилось так, что люди были неуважимы и полностью исключены из социальной жизни, особенно из социального контекста, и это было основано на их представлениях о человеке и обществе, которые были привиты индивидам, формирующим ментальную модель, которая поселяется в этом и больше не исчезает. Он просто преобразует (LOPES et al., 2009, c. 29).

RC: 97619

Доступно в: https://www.nucleodoconhecimento.com.br/закон/приоритетноеобслуживание 
Перспектива исторически достигнутых прав граждан принесла идею интеграции, интеграции, равенства как способа борьбы с процессами социальной изоляции, дискриминации и стигматизации. Этот процесс является основополагающим, как тротуары, которые гарантируют право приезжать и уходить любому гражданину в городе, где он живет.

В Бразилии этот процесс связан с признанием права на доступность. В главе VII Федеральной конституции статья 227 предусматривает «облегчение доступа к коллективным товарам и услугам с устранением архитектурных предрассудков и препятствий», тем самым имея правила, гарантирующие строительство приспособления мест, общественных зданий и общественного транспорта. (NOGUEIRA, 2010, с. 51). В 1981 году, например, Организация Объединенных Наций - ООН признала в конвенции Международный год людей с ограниченными возможностями. В 1989 году эти права были изменены Законом №. 7.853, цель которого состоит в установлении «судебной защиты коллективных или диффузных интересов этих лиц, дисциплинировании деятельности прокуратуры, определении преступлений и принятии других мер» (BRASIL, 1989). Этот же закон определяет соблюдение правил муниципалитетами в целях содействия функционированию зданий и дорог общего пользования для инвалидов.

Наконец, Федеральный закон №. 10098 от 19 декабря 2000[6] года, впоследствии регулируемый Декретом № 10 098. 5296 от 2 декабря 2004[7] года, стандартизируя вопрос о доступности как цели адаптации и институте доступа. Однако до настоящего времени этот закон не был осуществлен, поскольку такие вопросы, как доступ к общественным зданиям, постоянство и использование этих зданий, такие как образование и здравоохранение, не были полностью предусмотрены. Тротуары являются портретом общества, исключающего, что делает необходимым решение чрезвычайных проблем, таких как дыры на улицах, автомобили на тротуарах, прерывающие

$\mathrm{RC}: 97619$

Доступно в: https://www.nucleodoconhecimento.com.br/закон/приоритетноеобслуживание 
мобильность, стандартизация пандусов, поручней, пешеходных дорожек, общественных туалетов и специальных вывесок, чтобы проблемы доступности могли быть сведены к минимуму (COELHO, 2010).

В этом смысле право на доступность является незаменимым фрактором не только для тех, кто имеет какую-либо инвалидность или ограниченную мобильность, но и для общества в целом, поскольку на основе принципа равенства все равны перед законом и пользуются одинаковыми правами приходить и уходить, образование, досуг, жилье, туризм и культура. Согласно Декларации прав инвалидов, принятой на Генеральной Ассамблее Организации Объединенных Наций (ООН) в 1975 году, она провозглашает, среди прочего, что: «Инвалиды имеют право на меры, направленные на расширение их прав и возможностей стать максимально уверенными в себе».

Всемирная хартия права на город, одобренная на Социальном форуме Стран Северной и Южной Америки в Кито, Всемирном форуме городов в Барселоне в 2004 году и пятом Всемирном социальном форуме Порту-Алегри в 2005 году, устанавливает обязательства между правительствами и организованным гражданским обществом содействовать развитию городов на основе принципов солидарности, свободы, равенства, социальной справедливости и достоинства.

Право на город определяется в Хартии следующим образом: «Справедливое пользование городами в рамках принципов устойчивости, демократии и социальной справедливости [...] взаимозависимо от всех международно признанных прав». Город в этом документе задуман как «культурно богатое и разнообразное коллективное пространство, принадлежащее всем гражданам» ((CARTA MUNDIAL DO DIREITO À CIDADE, 2004, стр. 2). Что касается особой защиты уязвимых групп и лиц, то в Хартии города говорится:

Города посредством политики позитивного утверждения уязвимых групп должны преодолевать политические, экономические и социальные препятствия, которые

RC: 97619

Доступно в: https://www.nucleodoconhecimento.com.br/закон/приоритетноеобслуживание 
ограничивают свободу, справедливость и равенство граждан и которые препятствуют полному развитию человеческой личности и эффрективному участию в политической, экономической, культурной и социальной организации города (CARTA MUNDIAL DO DIREITO À CIDADE, 2004, c. 3).

Что касается городской мобильности, то статья 13 гласит:

1. Города гарантируют право на мобильность и передвижение в городе через систему и общественный транспорт, доступный для всех людей в соответствии с планом городских и междугородних поездок и, исходя из соответствующих видов транспорта, различных социальных потребностей (пол, возраст, инвалидность) и окружающей среды, с ценами, соответствующими доходам граждан. Будет поощряться использование незаражающих транспортных средств, а пешеходные зоны будут постоянно резервироваться в определенное время суток.

2. Города будут способствовать снятию архитектурных барьеров для внедрения необходимого оборудования для системы мобильности и циркуляции и адаптации всех общественных или общественных зданий, рабочих мест, для обеспечения доступности людей с особыми потребностями (CARTA MUNDIAL DO DIREITO À CIDADE, 2004, стр. 3).

Стоит отметить, что когда дело доходит до доступности, она не ограничивается фризическим пространством, где она установлена, это город в целом, который представляет политический, социальный, экономический и интеллектуальный процесс общества.

В области образования и здравоохранения подчеркивается, что школьная интеграция конфигурируется как право гражданина, гарантирующее универсально, подчеркивая в качестве вехи этого процесса Саламанкскую

$\mathrm{RC}: 97619$

Доступно в: https://www.nucleodoconhecimento.com.br/закон/приоритетноеобслуживание 
декларацию, в которой подчеркивается инклюзивное образование, следуя конвенциям и правам человека, направленным на детей и подростков, представляя здесь основные из них, как заслугу базовых знаний по предмету.Документ был назван в честь Всемирной конференции по специальному образованию в Саламанке в 1994 году, целью которой была реструктуризация реформы политики в соответствии с включением, заявив, что:

«Каждый ребенок имеет основополагающее право на образование, и ему должна быть предоставлена возможность достигать и поддерживать надлежащий уровень обучения, каждый ребенок имеет уникальные характеристики, интересы, навыки и потребности в обучении, следует назначать системы образования и осуществлять образовательные программы, с тем чтобы учитывать широкое разнообразие таких характеристик и потребностей, лица с особыми образовательными потребностями должны иметь доступ к обычной школе, которая должна быть в состоянии поддерживать их в рамках ориентированной на ребенка педагогики, способной удовлетворить такие потребности, обычные школы, которые имеют такое инклюзивное руководство, являются наиболее эфрфективным средством борьбы с дискриминационным отношением путем создания гостеприимных общин, построения инклюзивного общества и обеспечения образования для всех; кроме того, такие школы обеспечивают эфффективное образование для большинства детей и повышают эффрективность и, в конечном счете, стоимость эфффективности всей системы образования (...)» Так цитируется документ $(\mathrm{OOH}$, 2010, c. 78).

Эта декларация возлагает на нас обязанность предлагать и предоставлять возможности для детей и подростков конкретным программам и индивидуальной оценке, обеспечивая полное развитие и развитие потенциала каждого человека. Для этого следует рассмотреть вопрос о ингаптации учебной программы и предусмотреть гарантию закона.

Это международное соглашение о правах детей и подростков. Принимая во внимание, что в соответствии с принципами, провозглашенными в Уставе Организации Объединенных Наций, признание достоинства, присущего всем членам человеческой семьи, достоинства и равных и неотъемлемых прав 
является основой свободы, справедливости и мира во всем мире, и памятуя о том, что народы Организации Объединенных Наций подтвердили в своем Уставе свою уверенность в основных правах человека и достоинстве и ценности человеческой личности и определили содействовать социальному прогрессу и повышению уровня жизни при большей свободе.

В Национальной политике специального образования (PNEE) в перспективе инклюзивного образования (PEI) (2008 год) подчеркивается необходимость борьбы с сегрегацией учащихся в школьной среде и предлагается специальное образование, которое развивается взаимодополняющим образом, подтверждая уникальную систему образования.

В этом контексте права человека являются универсальными, и ни один гражданин не может быть исключен по какой-либо причине из-за их физического, психического состояния или цвета кожи, расы, обычаев или социального класса, поэтому власти должны разработать государственную политику, направленную на равное уходу за этими людьми.

Таким образом, признавая, что инвалиды имеют приоритеты, в том числе префреренциальный, быстрый и индивидуальный уход, они реализуют осуществление основных прав, закрепленных в Федеральной конституции 1988 года. Однако следует уточнить, что, поскольку это очень личное право, это право должно осуществляться в интересах инвалидов или лиц, которые находятся в уязвимом положении, в соответствии с Федеральным законом 10.048 от 8 ноября 2000[8] года, который одобряет приоритет ухода за лицами, в котором он указывает: инвалиды, беременные женщины, кормящие женщины, люди, сопровождаемые детьми на их жизнь, помимо пожилых людей.

Также свидетельствует, что личное состояние партии не является главной изюминкой Устава инвалида, испрашивается преференциальный, 
непосредственный и индивидуализированный уход за уязвимой частью, в нашем исследовании, инвалидом в нотариате.

\section{4. ПОЛОЖЕНИЕ ИНВАЛИДОВ И ПРИНЦИП ПРИОРИТЕТНОСТИ РЕГИСТРАЦИИ НЕДВИЖИМОСТИ}

В контексте нотариального и регистрационного обслуживания, помимо соблюдения основных принципов государственного управления, необходимо, чтобы нотариусы и регистраторы также соответствовали принципам, которые считаются специфическими для этой деятельности. Важно понимать, что принципы податливы, учитывая, что они приспосабливаются к историческим и социальным обстоятельствам, через которые они проходят.

Принципы, применяемые к регистрационным услугам, включают в себя действия, которые должны выполняться на протяжении всего процесса регистрации, от регистрации до рогации, связанные с законом о недвижимости. Принцип регистрации, согласно Carvalho (2011), является началом процесса, будучи ответственным за конституцию, передачу, изменение или исчезновение прав в рис. Таким образом, это запись актов, которые изменяют или отменяют любой акт регистрации.

Принцип рекламы, уже упомянутый в качестве основного принципа государственного управления, все еще рассматривается, и регистраторы должны обнародовать записи, сделанные в их нотариаториях. Согласно Ceneviva (2008), реклама как принцип регистрационной деятельности направлена на выполнение своей тройной фрункции, которая заключается в передаче регистрации в известность третьим лицам, информировании об активах и правах лиц, которые получают выгоды, вытекающие из акта регистрации, жертвуя, даже частично, своим правом на неприкосновенность частной жизни и близость и поощряя действия в статистических целях, национальные интересы или общественный контроль.

$\mathrm{RC}: 97619$

Доступно в: https://www.nucleodoconhecimento.com.br/закон/приоритетноеобслуживание 
Принцип презумпции истины, применяемый к зарегистрированным службам, также является результатом общественного веры, предоставленного им вместе с делегированием функции. Vasconcelos e Cruz (2000) разъясняют, что общественная вера должна распространяться на все действия, совершаемые в рамках регистрационных услуг, положительно реагируя на существование реальных прав. Таким образом, всегда предполагается, что все, что внесено в реестр недвижимости, является правдой, пока не доказано обратное.

В свою очередь, принцип приоритета касается вопроса о порядке внесения записей при регистрации недвижимости, а регистратор должен учитывать хронологический порядок представления титулов, согласно ст. 186 Закона № 6,015/1973. Antunes (2005) отмечает, что именно хронологический порядок должен определять приоритет названия и предпочтение реального права.

Принцип специальности или определения записей гласит, что регистрация должна быть произведена таким образом, чтобы описание имущества было точным и с его специфическими характеристиками, такими как регистрация, номер заказа, дата, идентификация имущества, противостояния, местоположение и площадь. Кроме того, необходимо также включить данные о его владельце, такие как имя, место жительства, национальность, семейное положение, профессия, общий регистрационный номер (RG) и, в случае юридического лица, должен быть включен в социальную компанию и номер Национального реестра юридических лиц (CNPJ). Правильное описание этих данных имеет важное значение для обеспечения правовой определенности совершаемых действий (ANTUNES, 2005).

Продолжение описания принципов зарегистрированных услуг имеет принцип квалификации, законности или легитимности, согласно Antunes (2005), регистратор должен проверить представленное название с учетом фрормы, действительности и соответствия закону. Galiani (1995) также упоминает, что даже для изучения предоставленного ему титула регистратор должен

$\mathrm{RC}: 97619$

Доступно в: https://www.nucleodoconhecimento.com.br/закон/приоритетноеобслуживание 
воспользоваться законодательством, не имея возможности выйти за пределы, установленные законом, и должен проанализировать только его формальные аспекты.

Принцип непрерывности также является частью перечня принципов, применяемых к регистрационным услугам, который был выделен Antunes (2005) в качестве одной из основ этих услуг. Что касается применения этого принципа, Balbino Filho (2001) поясняет, что он навешивает обязательство непрерывности регистрации, поддерживая связь между различными предприятиями, которые пришли к изменению правовой реальной ситуации. Таким образом, все изменения, которые происходят в названии, должны быть зафиксированы в одном документе, сохраняя предыдущую информацию.

Наконец, существует принцип инстанции или округации, который касается действий, предпринятых регистратором на основе просьбы сторон. Согласно Balbino Filho (2001), принцип инстанции или рогации касается подстрекательства к любому регистрационному акту и должен быть простым, независимым особым образом и может быть явным или молчаливым. Выражается, когда это четко выражено сторонами, и молчаливо, когда регистратор может определить волю сторон, пересказывая свой опыт.

С учетом вышесказанного регистрационные услуги должны осуществляться в соответствии с упомянутыми принципами, и нельзя забывать, что основные принципы государственного управления должны учитываться во всей деятельности, осуществляемой регистраторами в рамках их ффункций.

Дискуссии о принципе приоритета регистрации недвижимости были предметом обсуждения, настолько, что можно выявить рассмотренные дела, которые рассматривают конфликты с правами определенных публичных организаций. Lago (2016) ссылается на предоставление приоритета в уходе за адвокатами и предоставление приоритетного ухода пожилым людям, оба из Суда записей

$\mathrm{RC}: 97619$

Доступно в: https://www.nucleodoconhecimento.com.br/закон/приоритетноеобслуживание 
Сан-Паулу - SP. В первом было отказано из-за конкретного правового положения, касающегося закона 8.906/1994 - Устава Бразильской ассоциации адвокатов, и нарушения порядка старшинства, однако была вынесена рекомендация о предоставлении приоритетного ухода в тех случаях, когда нотариусы и зарегистрированные судьи, в соответствии с разумными критериями, необходимы.

Во втором случае магистраты использовали критерии, определенные Законом 6.015/1973 и Гражданским кодексом, заявив, что представленный приказ должен строго соблюдаться. При этом было оставлено понимание того, что приоритетная забота будет предоставляться пожилым людям при предоставлении сертификатов или при выдаче документов, но не при вводе титулов, которые могли бы генерировать приоритет (LAGO, 2016).

Из этого можно вынести такое понимание и в случае инвалидов, поскольку его Статут также предусматривает право на приоритетный уход. Было установлено, что, по мнению зарегистрированных судов, конкретное положение Закона № 6.015/1973 имеет преимущественную силу в отношении права на приоритетную опеку определенных аудиторий, поскольку оно касается материального права приоритета, поскольку понимается, что предоставление приоритетной опеки вне требований ст. 186 Закона № 6.015/1973 будет представлять собой неоспоримое признание внеправовых оснований, что поставило бы под угрозу служение праву на равенство, что также является предпосылкой Статута инвалидов.

Принцип приоритета заложен в искусстве. 182 и последующие положения Закона № 6.015/73. Упоминается, например, его отношение к ипотеке и актам, связанным с ней, хотя и излишним, также содержится в гражданском кодексе, в статье 1493, in verbis: «Записи и индоссаменты должны следовать порядку, в котором они запрашиваются, подтверждая их последовательную нумеровку в протоколе». Таким образом, нет возможности для запроса лица с

$\mathrm{RC}: 97619$

Доступно в: https://www.nucleodoconhecimento.com.br/закон/приоритетноеобслуживание 
ограниченными возможностями о том, чтобы его запрос был выполнен до тех, кто его сменил в нотариальном порядке. В этом смысле Afrânio Carvalho (2011):

(...) в споре о веховых правах на имущество не все они занимают одинаковый ранг, но заканчивают или квалифицируются по соотношению старшинства, основанному на хронологическом порядке его появления: prior tempore potior jure. В зависимости от времени, в которое они возникают, права занимают позицию в реестре, превалируя над теми, которые ранее установлены, над теми, которые приходят после. (CARVALHO, 2011, с. 216).

Разъясняется, что титулы, порождаемые приоритетным правом, должны поступать в Реестр недвижимости после их опубликования в Книге № 1 Протокол в соответствии со строгим порядком представления, описанным в Законе о публичных записях. По этой причине любое право на льготный уход в связи с инвалидностью, возрастом, полом не позволяет, с точки зрения этих званий, быть полученным раньше других, которые уже вошли в помещение службы в первую очередь. Применяя принцип приоритета регистрации, правовой титул должен быть зарегистрирован, в первую очередь, в соответствии с наименьшим протокольным номером, «подавляющим регистрацию представленных позднее, на срок, соответствующий по крайней мере одному рабочему дню» (Закон 6.015/73, статья 191). Однако, хотя принцип приоритета инвалидов не применяется, в обоих случаях титулы должны быть зарегистрированы.

Для решения проблемы Lago (2016, с. 316) предлагает «систему системы, состоящую из устройства поставщика паролей с определенными характеристиками и двух одновременных протокольных книг - одной предварительной и одной окончательной». Однако считается, что проблема выходит за рамки, будучи недостаточной для решения, учитывая автономию регистрационной системы и намерение промульгировать Статут инвалидов, при этом понимается, что приоритетная помощь в этом случае не должна иметь место, иначе это нанесло бы ущерб праву на равенство.

RC: 97619

Доступно в: https://www.nucleodoconhecimento.com.br/закон/приоритетноеобслуживание 


\section{5. ЗАКЛЮЧЕНИЕ}

Нотариусы и регистрационные службы были рассмотрены в настоящем исследовании, рассматривая их в своей деятельности, осуществляемой частной сферой делегированием государственной власти, принимая во внимание ориентацию на социальные интересы, следовательно, из-за подчинения общим принципам государственного управления, в дополнение к принципам, характерным для этой деятельности, которые должны соблюдаться в каждом акте.

В дополнение к подчинению конкретным принципам этой деятельности, которые заключаются в том, что касается надписи, публичности, презумпции истины, приоритета, специальности или определения записей, квалификации, законности или легитимности, непрерывности и инстанции или рогации, а также публичной веры, которая является одной из основных упомянутых в прецедентном праве.

Этот вопрос рассматривался с точки зрения того, что, хотя права инвалидов гарантируются Федеральной конституцией, реальность свидетельствует о большой дистанции между формальными правами и их эффективностью, что свидетельствует о том, что на протяжении всей истории существовали многочисленные государственные стратегии, направленные на инвалидов в поисках доступности. однако мобильность и равенство прав, интеграция их в общество, очевидно, что для эффрективного осуществления их прав еще предстоит идти по значительному пути.

В рамках системы регистрации было установлено, что существует коллизия между еe положениями принципа приоритета регистрации и Статутом инвалидов, который предусматривает приоритетную помощь этой общественности. Получается, что в этой системе материальные права сосредоточены, поэтому рассмотрение Статута инвалидов на приоритетный

$\mathrm{RC}: 97619$

Доступно в: https://www.nucleodoconhecimento.com.br/закон/приоритетноеобслуживание 
уход будет иметь такие последствия, как возможность обхода или обмана действующей в стране правовой системы.

Таким образом, из аналогичных решений, принятых регистрами Сан-Паулу, было установлено, что конкретное положение Закона № 6.015/1973 имеет преимущественную силу в отношении права на приоритетную опеку некоторых публичных лиц, поскольку оно касается материального права приоритета, поскольку понимается, что предоставление приоритетного ухода выходит за рамки требований ст. 186 Закона № 6.015/1973, будет представлять собой неоспоримое признание оскорбления реальных прав граждан, что поставит под угрозу служение праву на равенство, что также является предпосылкой Статута инвалидов.

Наконец, в качестве способа ответа на вопрос, который является руководством настоящего эссе, признается, что гарантия механизма приоритета регистрации не контрастирует с общеустановленной в Статуте инвалидов кафедрой. Правила этого не налагаются на нормы Закона 6.015/1973. Они имеют дело с такими дипломами в разных ситуациях. Другими словами, стоит охранная норма до предела, чтобы она не исключалась другим, общественного порядка, который оскверняет заинтересованным сторонам, регистральный приоритет и в отдаленном конце предпочтение и определение везрательных прав.

\section{ИСПОЛЬЗОВАННАЯ ЛИТЕРАТУРА}

ANTUNES, Luciana Rodrigues. Introdução ao Direito Notarial e Registral. Jus Navigandi, Teresina, ano 9, n. 691, 2005.

BIANCHETTI, Lucídio; FREIRE, Ida Mara (orgs.). Um olhar sobre a diferença: interação, trabalho e cidadania. 6. ed. São Paulo: Papirus. 2007.

BRASIL. Constituição da República Federativa do Brasil, de 05 de outubro de 1988.

Brasília, 1988. Diário Oficial da União. Disponível em:

$\mathrm{RC}: 97619$

Доступно в: https://www.nucleodoconhecimento.com.br/закон/приоритетноеобслуживание 
http://www.planalto.gov.br/ccivil_03/Constituicao/Constituicao.htm Acesso em: julho.2021.

BRASIL. Decreto n 5.296 de 2 de dezembro de 2004. Diário Oficial da União, 3 dez. 2004. Disponível em: http://www.planalto.gov.br/ccivil_03/_ato20042006/2004/decreto/d5296.htm . Acesso em: 25 jul. 2021.

BRASIL. Lei n. 13.105, de 16 de março de 2015. Disponível em: $<$ https://www.planalto.gov.br/ccivil_03/_ato2015-2018/2015/lei/13105.htm> Acesso em: jul.2021.

BRASIL. Lei o 10.406, de 10 de janeiro de 2002. Institui o Código Civil. Diário Oficial da União: seção 1, Brasília, DF, ano 139, n. 8, p. 1-74, 11 jan. 2002.

BRASIL. Lei ㄲo. 10.048, de 08 de Novembro de 2000. Diário Oficial [da República Federativa do Brasil], Brasília. Disponível em: https://www.presidencia.gov.br/ccivil_03/Leis/L10048.htm . Acesso em: 30jul.2021.

BRASIL. Lei №. 10.098, de 19 de Dezembro de 2000. Diário Oficial [da República Federativa do Brasil], Brasília. Disponível em: https://www.presidencia.gov.br/ccivil_03/Leis/L10098.htm . Acesso em: 30jul.2021.

BRASIL. Presidência da República. Lei 7.853 de 24 de outubro de 1989. Disponível em:http://www.planalto.gov.br/ccivil_03/leis/17853.htm - Acesso em 26/07/2021.

CARTA Mundial do Direito à Cidade. Fórum Social das Américas - Quito - Julho 2004; Fórum Mundial Urbano - Barcelona - Setembro 2004; V Fórum Social Mundial - Porto Alegre - Janeiro 2005. Disponível em: Acesso em: 30 jul. 2021.

CARVALHO, Afrânio de. Registro de imóveis. Rio de Janeiro: Editora Forense, 2011.

RC: 97619

Доступно в: https://www.nucleodoconhecimento.com.br/закон/приоритетноеобслуживание 
CENEVIVA, Walter. Lei dos notários e registradores comentada. São Paulo: Saraiva, 2008.

CLEMENTE, Carlos Aparício. Lei de cotas para o trabalho de pessoas com deficiência: Análise e fundamentação dos principais argumentos favoráveis e contrários ao seu cumprimento. 2015.

GALIANI, Luiz Antônio. Os princípios basilares do fólio real. RJ n. 212, jun/95.

GOFFMAN, Erving. Estigma: notas sobre a manipulação da identidade deteriorada. 4⿳⺈. ed. Rio de Janeiro:LTC, 2008.

GUGEL, Maria Aparecida. Benefício da prestação continuada e trabalho: Mudanças da Lei № 12.470, de 31 de agosto de 2011. Disponível em: Acesso em jul.2021.

KOYAMA, D. B. Os reflexos da lei 13.146/2015 - Estatuto da Pessoa com Deficiência - no sistema jurídico brasileiro. Universidade Presbiteriana Mackenzie, São Paulo, 2017.

LAGO, Ivan Jacopetti do. O atendimento prioritário da Lei Federal 13.146/2015 (Estatuto da Pessoa Com Deficiência) e o princípio da prioridade do registro de imóveis.Revista de Direito Imobiliário,São Paulo, ano 39, v.80, jan-jun.2016.

LORENTEZ, Lutiana Nacur. A norma da igualdade e o trabalho das pessoas portadoras de deficiência. São Paulo: LTr, 2006.

MAINIERI, Tiago; ROSA, Elisa Costa Ferreira. Comunicação pública, cidadania e democracia-algumas reflexões. Revista Comunicação Midiática, v. 7, n. 1, p. p. 192-206, 2012.

ORGANIZAÇÃO DAS NAÇÕES UNIDAS (ONU). Declaração de Direitos do Deficiente Mental - 1971. Aprovada pela resolução n. A/8429 da Assembleia Geral

RC: 97619

Доступно в: https://www.nucleodoconhecimento.com.br/закон/приоритетноеобслуживание 
da ONU de 22 de dezembro de 1971. Disponível em: http://www.direitoshumanos.usp.br/index.php/Direito-dos-Portadores-deDefici\%C3\%AAncia/declaracao-de-direitos-do-deficiente-mental.html. Acesso em 27/07/2021.

SILVA, C. H. R. Teoria das Incapacidades. [online]. 2008. Disponível em: <http://www.ribeirodasilva.pro.br/teoriadasincapacidades.html> Acesso em: jul.2021.

VASCONCELOS, Julenildo Nunes; CRUZ, Antônio Augusto Rodrigues. Direito notarial: teoria e prática. [S.I.] Juarez de Oliveira, 2000.

\section{ПРИЛОЖЕНИЕ - СПРАВОЧНАЯ СНОСКА}

4. Комплекс правовых мер по защите ситуаций в процессе создания, изменения или ликвидации.

5. Комплекс правовых мер, предлагаемых для сохранения сложившихся ситуаций

6. Он устанавливает общие стандарты и основные критерии для содействия доступности для людей с ограниченными возможностями или ограниченной мобильностью, а также предусматривает другие меры.

7. Он регулирует законы в 10048 от 8 ноября 2000 года, в которых приоритет отдается заботе о людях, которые он определяет, и 10098 от 19 декабря 2000 года, в котором устанавливаются общие стандарты и основные критерии для содействия доступности для инвалидов или лиц с ограниченной мобильностью, а также предусматриваются другие меры.

8. Он отдает приоритет заботе о людях, которых он определяет, и предусматривает другие меры.

$\mathrm{RC}: 97619$

Доступно в: https://www.nucleodoconhecimento.com.br/закон/приоритетноеобслуживание 
Представлено: Июль 2021 года.

Утвержден: Сентябрь 2021 года.

RC: 97619

Доступно в: https://www.nucleodoconhecimento.com.br/закон/приоритетноеобслуживание 